\title{
Paracrine regulation of fat cell formation in bone marrow cultures via adiponectin and prostaglandins
}

\author{
Takafumi Yokota, ${ }^{1}$ C.S. Reddy Meka, ${ }^{1}$ Kay L. Medina,,${ }^{1}$ Hideya Igarashi, ${ }^{1}$ Phillip C. Comp, ${ }^{2}$ \\ Masahiko Takahashi, ${ }^{3}$ Makoto Nishida, ${ }^{3}$ Kenji Oritani, ${ }^{3}$ Jun-ichiro Miyagawa, ${ }^{3}$ \\ Tohru Funahashi, ${ }^{3}$ Yoshiaki Tomiyama, ${ }^{3}$ Yuji Matsuzawa, ${ }^{3}$ and Paul W. Kincade ${ }^{1}$
}

\author{
${ }^{1}$ Immunobiology and Cancer Program, Oklahoma Medical Research Foundation, Oklahoma City, Oklahoma, USA \\ ${ }^{2}$ Department of Medicine, University of Oklahoma Health Sciences Center, Oklahoma City, Oklahoma, USA \\ ${ }^{3}$ Department of Internal Medicine and Molecular Science, Graduate School of Medicine, Osaka University, Osaka, Japan \\ Address correspondence to: Paul W. Kincade, Immunobiology and Cancer Program, \\ Oklahoma Medical Research Foundation, 825 NE 13th Street, Oklahoma City, Oklahoma 73104, USA. \\ Phone: (405) 271-7905; Fax: (405) 271-8568; E-mail: Kincade@omrf.ouhsc.edu.
}

Received for publication October 25, 2001, and accepted in revised form April 9, 2002.

\begin{abstract}
Adiponectin, an adipocyte-derived hormone, was recently shown to have potential therapeutic applications in diabetes and obesity because of its influence on glucose and lipid metabolism. We found that brown fat in normal human bone marrow contains this protein and used marrowderived preadipocyte lines and long-term cultures to explore potential roles in hematopoiesis. Recombinant adiponectin blocked fat cell formation in long-term bone marrow cultures and inhibited the differentiation of cloned stromal preadipocytes. Adiponectin also caused elevated expression of cyclooxygenase-2 (COX-2) by these stromal cells and induced release of prostaglandin $\mathrm{E}_{2}$ $\left(\mathrm{PGE}_{2}\right)$. The COX-2 inhibitor Dup-697 prevented the inhibitory action of adiponectin on preadipocyte differentiation, suggesting involvement of stromal cell-derived prostanoids. Furthermore, adiponectin failed to block fat cell generation when bone marrow cells were derived from B6,129S $S^{\text {Ptgs2tm1jed }}\left({\mathrm{COX}-2^{+} /-}_{)}\right.$mice. These observations show that preadipocytes represent direct targets for adiponectin action, establishing a paracrine negative feedback loop for fat regulation. They also link adiponectin to the COX-2-dependent PGs that are critical in this process.
\end{abstract}

J. Clin. Invest. 109:1303-1310 (2002). doi:10.1172/JCI200214506.

\section{Introduction}

Multiple functions attributed to adipose tissue include thermoregulation, energy storage, estrogen synthesis, and cytokine production. While fat cells and their precursors have been the focus of many studies involving obesity, they also constitute a normal component of bone marrow. Indeed, adipocytes, hematopoiesis-supporting stromal cells, osteoblasts, and myocytes appear to derive from common mesenchymal stem cells in that tissue (1). Cloned preadipocyte lines with the potential for differentiation in culture have been extremely valuable for understanding the molecular regulation of differentiation (2). Agents that induce fat cell formation from these precursors include insulin, hydrocortisone, methylisobutylxanthine (MIBX) (3), and ligands for peroxisome proliferator activator receptors (PPARs) $(4,5)$. On the other hand, many findings indicate that adipogenesis is also controlled through negative feedback mechanisms. For example, adipose tissue produces leptin (6), plasminogen activator inhibitor type 1 (PAI-1) (7), TNF- $\alpha$ (8), TGF- $\beta$ (9), and prostaglandin $\mathrm{E}_{2}\left(\mathrm{PGE}_{2}\right)(10)$, agents that are thought to block fat cell formation (11-14).

Four groups independently discovered a protein designated Acrp30, adipoQ, or adiponectin that represents a major fat cell-restricted product in mouse and man
(15-18). It was also isolated from human serum and termed GBP28 (18). Adiponectin is a homotrimer that is similar in size and overall structure to complement protein $\mathrm{C} 1 \mathrm{q}$, with particularly high homology in the C-terminal globular domain (17). The crystal structure of adiponectin revealed additional high similarity between the same domain and TNF- $\alpha$ (19). Adiponectin synthesis increases with adipocyte differentiation in culture and is inhibited by TNF- $\alpha$ (20). Adipocytes use a specialized secretory compartment to release this protein (21).

Normal biological activities of adiponectin are poorly understood, but provocative findings suggest potential involvement in obesity, cardiovascular disease, and diabetes. Production and circulating protein concentrations are suppressed in obese mice and humans (16, 22). Low plasma levels may be a risk factor in coronary heart disease, and concentrations are also significantly reduced in type 2 diabetes $(23,24)$. The ability of adiponectin to lower glucose and reverse insulin resistance suggests that it may have application as a diabetes drug $(25,26)$. Furthermore, a proteolytically cleaved fragment of adiponectin was shown to cause weight loss in obese animals (27). This protein directly or indirectly affects at least four cell types. Adiponectin modulates NF- $\mathrm{KB}$-mediated signals in human aortic 
endothelial cells, presumably accounting for their reduced adhesiveness for monocytes (28). The protein suppresses differentiation of myeloid progenitor cells and has discrete effects on two monocyte cell lines (29). Adiponectin reduces the viability of these cells and blocks LPS-induced production of TNF- $\alpha$. It appears to use the $\mathrm{C} 1 \mathrm{qR}$ p receptor on normal macrophages and blocks their ability to phagocytose particles (29). Intact or cleaved forms of adiponectin cause increased fatty acid oxidation by muscle cells in treated mice $(25,27)$. The protein may also induce metabolic changes in hepatocytes $(25,26)$.

Fat cells are conspicuous in normal bone marrow and have long been suspected to have an influence on hematopoiesis (30). Indeed, adipogenesis alters expression of extracellular matrix and cytokines in bone marrow, affecting hematopoiesis both directly and indirectly. Preadipocytes support blood cell formation in culture, and fully differentiated fat cells produce less colony stimulating factor- 1 than their precursors do (31). Hematopoiesis-supportive activity and expression of stem cell factor, IL-6, and leukemia inhibitory factor declined with terminal adipocyte differentiation of an embryo-derived stromal line (32). The fat cell product leptin promotes osteoblast formation and hematopoiesis while inhibiting adipogenesis $(11,33)$. Furthermore, adiponectin was found to block myelopoiesis in clonal assays of hematopoietic cell precursors (29). All these observations suggest that marrow fat cells and their products may participate in the regulation of blood cell formation, but more information is needed regarding mechanisms. We now report that recombinant adiponectin blocks fat cell formation in complex long-term bone marrow cultures (LTBMCs). This response appears to result from the induction of cyclooxygenase-2 (COX-2) and PGs in preadipocytes.

\section{Methods}

Production and characterization of recombinant adiponectin. Human recombinant adiponectin was prepared as previously described (22). Briefly, a 693-bp adiponectin cDNA encoding a peptide leader-deficient protein was subcloned into the pET3c expression vector and used to transform host E. coli (strain BL21(DE3)pLysS). Synthesis of recombinant adiponectin was induced by isopropylthio- $\beta$-D-galactoside. Bacterial cells were pelleted and suspended in $50 \mathrm{mM}$ Tris- $\mathrm{HCl}(\mathrm{pH}$ 8.0) for 1 hour and added to Triton X-100 at a final concentration of $0.2 \%$, then sonicated. The suspended buffer was centrifuged and the pellet was then washed with the same solution. The pellet was precipitated and solubilized with $100 \mathrm{mM}$ Tris- $\mathrm{HCl}(\mathrm{pH} 8.0)$ containing $7 \mathrm{M}$ guanidine $\mathrm{HCl}$ and $1 \% \beta$-mercaptoethanol. The solubilized protein was refolded in the presence of $200 \mathrm{vol}-$ umes of $2 \mathrm{M}$ urea and $20 \mathrm{mM}$ Tris- $\mathrm{HCl}$ ( $\mathrm{pH}$ 8.0) for 3 days at $4^{\circ} \mathrm{C}$. The refolded protein was concentrated by centrifugal filtration and dialyzed with $20 \mathrm{mM}$ Tris$\mathrm{HCl}$ ( $\mathrm{pH}$ 8.0). It was purified by a Tris- $\mathrm{HCl}(20 \mathrm{mM}$, $\mathrm{pH}$ 7.2) -equilibrated DEAE-5PW ion-exchange high performance liquid chromatography column (Toso Co., Tokyo, Japan) using a linear gradient of $\mathrm{NaCl}(0-1$ M). SDS-PAGE and Western blotting with adiponectin-specific monoclonal antibodies were used to confirm adiponectin purity (see Figure 2). The distribution of its multimeric forms and their formula weights were examined by gel filtration chromatography using a Superdex 200 HR 10/30 column (Amersham Pharmacia Biotech, Piscataway, New Jersey, USA). Recombinant glutathione $S$ transferase (GST) was also prepared from E. coli and used as a control. The proteins were dialyzed with PBS and used at a concentration of $10 \mu \mathrm{g} / \mathrm{ml}$ in culture. After the cell sonication step, all procedures were performed in endotoxin-free buffers; final endotoxin concentrations were less than 0.07 endotoxin units/ml as checked by Limulus Amebocyte Lysate Pyrogent Plus (BioWhittaker Inc., Walkersville, Maryland, USA).

Reagents. Human insulin was purchased from Roche Diagnostics (Mannheim, Germany). MIBX was purchased from Sigma-Aldrich (St. Louis, Missouri, USA). $\mathrm{PGE}_{2}$ and Dup-697 were purchased from Cayman Chemical Co. (Ann Arbor, Michigan, USA) and used at a concentration of $1 \times 10^{-6} \mathrm{M}$.

Tissue, cells, and mice. Normal human bone marrow was collected by biopsy from the posterior iliac crest of healthy young volunteers with informed consent and used for immunohistochemical analysis of adiponectin. BMS2 and 3T3-L1 cells were maintained in DMEM (high glucose) supplemented with $10 \%$ FCS (HyClone Laboratories, Logan, Utah, USA). MS5 cells were maintained in $\alpha$-MEM medium supplemented with $10 \%$ FCS. Balb/c mice (3-6 weeks old) were obtained from Charles River Laboratories (Wilmington, Massachusetts, USA). B6,129S $\mathrm{S}^{\mathrm{Ptg} 2 \mathrm{tm} 1 \mathrm{Jed}}\left(\mathrm{COX}-2^{+-}\right)$ mice and C57BL/6 mice (3-5 weeks old) were purchased from The Jackson Laboratory (Bar Harbor, Maine, USA). High mortality and unavailability precluded use of homozygous COX-2-/ animals in these experiments, but a single targeted allele abrogated preadipocyte responses to adiponectin (see Figure 5).

Adiponectin expression in bone marrow. Expression of adiponectin protein was examined in normal human bone marrow specimens by indirect immunofluorescence methods using the 9108 monoclonal antibody provided by Otsuka Pharmaceutical Co. (Tokushima, Japan) (22). RT-PCR was used to detect adiponectin transcripts in cDNA prepared from total human bone marrow RNA (CLONTECH Laboratories Inc., Palo Alto, California, USA). The oligonucleotide primers were $5^{\prime}$-TGTTGCTGGGAGCTGTTCTACTG- $3^{\prime}$ and $5^{\prime}$ ATGTCTCCCTTAGGACCAATAAG- $3^{\prime}$ for adiponectin, and $5^{\prime}$-CCATCCTGCGTCTGGACCTG-3' and 5'-GTAACAGTCCGCCTAGAAGC- $3^{\prime}$ for $\beta$-actin.

LTBMCs. LTBMCs that support formation of myeloid cells (Dexter cultures) were initiated and maintained by published methods (34). Bone marrow cells of normal $\mathrm{Balb} / \mathrm{c}$ mice $\left(12 \times 10^{6}\right.$ cells $)$ were cultured in $25-\mathrm{cm}^{2}$ flasks in $5 \% \mathrm{CO}_{2}$ at $33^{\circ} \mathrm{C}$. The medium consisted of 
$\alpha$-MEM supplemented with $100 \mathrm{nM}$ hydrocortisone and 20\% horse serum (HyClone Laboratories). Cultures were treated with adiponectin or BSA beginning at culture initiation and weekly thereafter for 6 weeks. In some experiments, adiponectin was omitted from the media after 6 weeks of culture, and cultures were maintained for another 6 weeks with medium alone.

RT-PCR. Total RNA was isolated from MS5 or BMS2 cells treated with adiponectin for various periods using TRIzol reagent (Life Technologies Inc., Grand Island, New York, USA) and suspended in diethylpyrocarbonate-treated water. After treating total RNA with DNase (Life Technologies Inc.), cDNA was made using random hexamers and Moloney murine leukemia virus reverse transcriptase (Life Technologies Inc.). For PCR, $10 \mu \mathrm{l}$ of the reverse transcription mixtures described above were added to PCR buffer containing $1.5 \mathrm{mM} \mathrm{MgCl}_{2}, 1 \mathrm{U}$ Taq polymerase (PE Biosystems, Norwalk, Connecticut, USA), $2 \mathrm{mM}$ each of dNTP, and $200 \mathrm{nM}$ each of relevant sense and antisense primers. The DNA in the PCR reaction mixtures was amplified using $25-35$ cycles of $94^{\circ} \mathrm{C}$ for 1 minute, $55^{\circ} \mathrm{C}$ for 2 minutes, and $72^{\circ} \mathrm{C}$ for 3 minutes. The oligonucleotide primers used for these reactions were $5^{\prime}$-GCAAATCCTTGCTGTTCCAAT$3^{\prime}$ (sense) and 5'-GGAGAAGGCTTCCCAGCTTTT-3' (antisense) for COX-2, and $5^{\prime}$-CCCAGAGTCATGAGTCGAAGGAG-3' (sense) and 5'-CAGGCGCATGAGTACTTCTCGG-3' (antisense) for COX-1. Primers for TNF- $\alpha$, TGF- $\beta$, IFN- $\alpha$, IFN- $\beta$, IFN- $\gamma$, and limitin (35) were also prepared and used in this study.

Northern blot analysis. Poly $(\mathrm{A})^{+} \mathrm{mRNA}$ was prepared from the indicated samples using oligo(dT) columns (Ambion Inc., Austin, Texas, USA). Aliquots of poly(A) ${ }^{+}$ mRNA $(2 \mu \mathrm{g})$ were denatured in formamide and formaldehyde at $65^{\circ} \mathrm{C}$ and electrophoresed on formaldehyde-containing agarose gels. After capillary transfer to nylon membranes (Micron Separations Inc., Westborough, Massachusetts, USA), the RNA was crosslinked by UV exposure. CDNA probes for CCAAT/enhancer binding protein- $\alpha($ C/EBP- $\alpha)$ and adipocyte P2 (aP2) were obtained from ResGen (Huntsville, Alabama, USA) and American Type Culture Collection (Manassas, Virginia, USA), respectively. Probes with sizes corresponding to PPAR- $\gamma$, COX- 1 , and COX-2 were prepared using PCR, and all probes were radiolabeled with $\left[\alpha_{-}{ }^{32} \mathrm{P}\right] \mathrm{dCTP}$ using the random prime labeling system Rediprime II, purchased from Amersham Pharmacia Biotech.

Enzyme immunoassay for $\mathrm{PGE}_{2}$. Confluent MS5 or BMS2 cells prepared in 24-well plates were incubated in $500 \mu \mathrm{l}$ of media with or without adiponectin. Supernatants from these cultures were examined for the presence of $\mathrm{PGE}_{2}$ using an enzyme immunoassay kit purchased from Cayman Chemical Co.

Adipocyte differentiation. Differentiation of BMS2 cells to adipocytes was achieved by treatment with $5 \mu \mathrm{g} / \mathrm{ml}$ insulin and $0.5 \mathrm{mM}$ MIBX for 10 days. Differentiation of MS5 cells to adipocytes was achieved by treatment with $5 \mu \mathrm{g} / \mathrm{ml}$ insulin alone for 15 days. Cultures were treated with adiponectin, $\mathrm{PGE}_{2}$, or Dup-697 from the time of culture initiation. At the end of this period, cultures were photographed and then stained with Nile red to detect lipid accumulation indicative of adipocyte differentiation. The extent of differentiation was estimated by flow cytometry (FACScan; Becton Dickinson and Co., San Jose, California, USA) (35).

Adherent bone marrow cell cultures. Adherent bone marrow cell cultures were established with heterozygous knockout $\mathrm{COX}-2^{+/-}$mice or normal C57BL/6 mice. Bone marrow cells were suspended at $2 \times 10^{5}$ cells per 6 $\mathrm{ml}$ of Dexter culture media and seeded in $25-\mathrm{cm}^{2}$ flasks. This cell concentration gives rise to adherent stromal layers without myeloid cell growth. Cultures were treated with adiponectin or BSA at the time of culture initiation and weekly thereafter for 6 weeks.

\section{Results}

Adiponectin inhibits fat cell formation in LTBMCs. Adult bone marrow, like fetal and neonatal tissues, contains brown fat (30). Adiponectin was originally discovered as a product of subcutaneous white fat, and we used RT-PCR to determine whether it is also expressed in adult bone marrow. The adiponectin-specific primers yielded an amplification product from normal adult marrow cDNA (Figure 1a). We confirmed the specificity of amplification by sequencing the PCR product (data not shown). We also used an adiponectin-specific monoclonal antibody to determine whether the protein is present in human bone marrow (Figure 1b). Specific staining was found to be associated with the abundant fat cells in that tissue.

Monomeric recombinant adiponectin has an apparent molecular mass of $32 \mathrm{kDa}$ (ref. 22 and Figure 2a). We observed additional $64-\mathrm{kDa}$ and faint $96-\mathrm{kDa}$

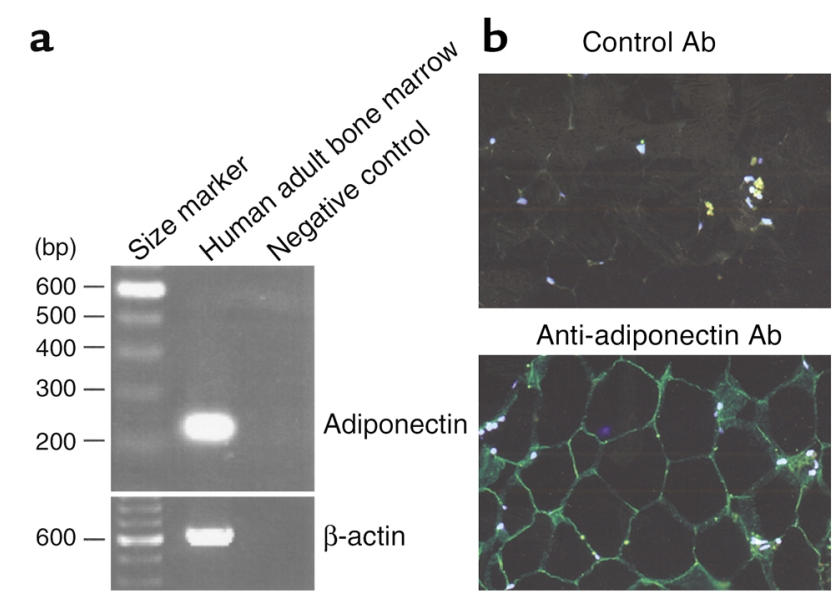

\section{Figure 1}

Adiponectin is present in normal human bone marrow. (a) Total RNA derived from normal human bone marrow was analyzed by RT-PCR. Samples containing all reagents except human bone marrow cDNA were used as negative controls. (b) Normal human bone marrow was processed and stained with a monoclonal antibody to adiponectin or an isotype-matched irrelevant control antibody. 
a

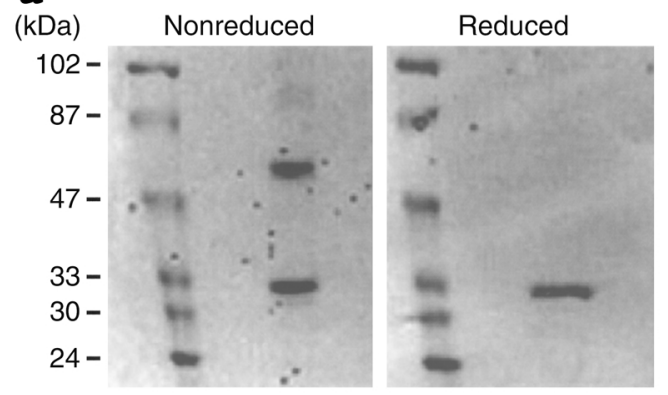

b

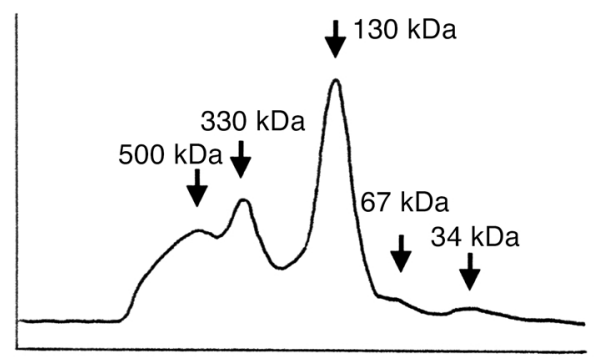

C

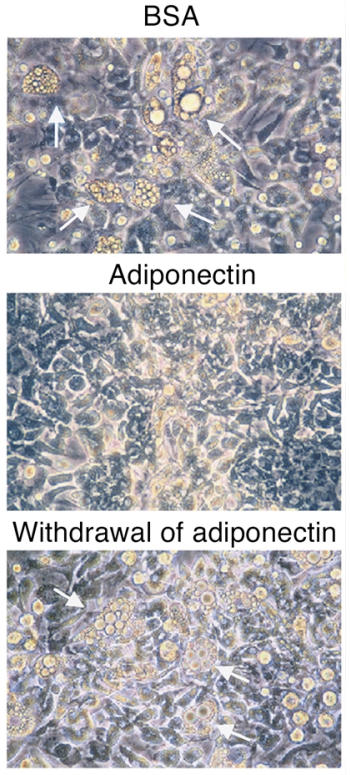

\section{Figure 2}

Recombinant adiponectin inhibits adipogenesis in culture. (a) Recombinant adiponectin (right lanes) was subjected to SDS-PAGE under either nonreducing or reducing conditions and stained with Coomassie brilliant blue. Protein size markers are shown for comparison (left lanes). (b) Analytical gel filtration chromatography was performed with recombinant adiponectin. Arrows indicate the apparent molecular weight of each peak. (c) Fat cell formation in adherent layers of Dexter cultures (top and middle panels, at 6 weeks; bottom panel, at 12 weeks from initiation of culture) is shown in these phasecontrast micrographs. Adiponectin was withdrawn after 6 weeks of culture (bottom panel). Arrows in each picture indicate adipocytes. The data is representative of that obtained in three similar experiments. bands on SDS-PAGE gels under nonreducing conditions, corresponding to dimers and trimers of adiponectin, respectively. No bands were detected above the $102-\mathrm{kDa}$ marker. The $64-\mathrm{kDa}$ and $96-\mathrm{kDa}$ bands disappeared under reducing conditions, and only the $32-\mathrm{kDa}$ band remained (Figure 2a). Adiponectin-specific monoclonal antibodies recognized all bands in both conditions by Western blotting (data not shown). Although multimeric structures larger than trimers were not detected by SDS-PAGE, gel filtration chromatography showed a wide distribution of recombinant adiponectin with formula weights exceeding trimers (Figure $2 \mathrm{~b}$ ). This multimeric character was consistent with native adiponectin in human plasma (22), as well as native or recombinant ACRP30, the murine homologue of adiponectin $(15,27)$.

To determine whether adiponectin influences blood cell formation, we established LTBMCs with and without this factor. We chose Dexter culture conditions, where adipocytes are typically conspicuous in the adherent layer. While no influence on myelopoiesis was found, inclusion of adiponectin in the medium completely inhibited fat cell formation (Figure 2c). The negative influence of this protein was reversible, and normal numbers of adipocytes were generated when the protein was removed. Additional studies were conducted to determine what cell types were influenced by adiponectin and to explore potential regulatory mechanisms.

Bone marrow cultures represent a complex mixture of hematopoietic cells that mature through interactions with an adherent stromal layer composed of fibroblasts, adipocytes, macrophages, and endothelial cells (34). Preliminary experiments with three preadipocyte cell lines suggested that preadipocytes could be one target of adiponectin in the bone marrow cultures. The 3T3-L1 cell line rapidly generated adipocytes when insulin was added as an adipogenesis-inducing agent, and this response was only slightly inhibited by adiponectin. However, substantial suppression was found with MS5 and BMS2 clones (see below). These experiments demonstrate that preadipocytes can be a direct target of this fat cell product.

Adiponectin induces COX-2 and $P G E_{2}$ synthesis. TNF- $\alpha$, TGF- $\beta$, IFNs, and $\mathrm{PGE}_{2}$ are fat cell products previously shown to inhibit fat cell formation. Thus, we screened for their induction in adiponectin-treated preadipocytes by RT-PCR analysis. Transcripts corresponding to TNF- $\alpha$ or IFN- $\gamma$ were not detectable in MS5 cells, even when adiponectin was added to the cultures (data not shown). Basal expression of TGF- $\beta$, IFN- $\alpha$ and $-\beta$, and a newly described IFN-like cytokine designated limitin
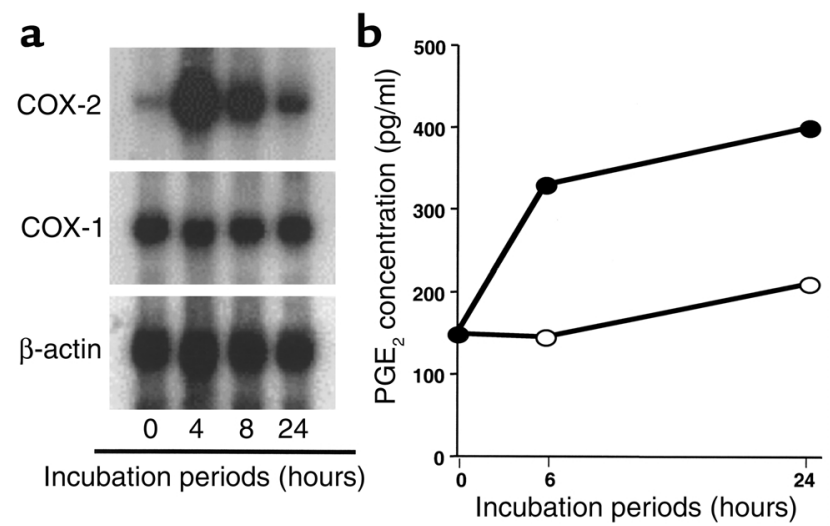

\section{Figure 3}

Adiponectin induces the COX-2-prostanoid pathway in preadipocytes. (a) Northern blot analysis of COX-2 and COX-1 expression in BMS2 cells treated with adiponectin. (b) Adiponectin upregulates $\mathrm{PGE}_{2}$ secretion by BMS2 cells (open circles, BSA; closed circles, adiponectin). The data are presented as the mean of duplicate cultures. Similar results were obtained in four independent experiments. 
a

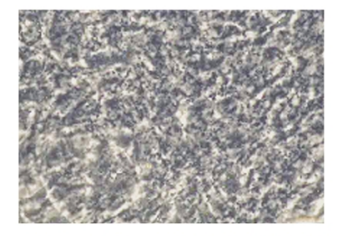

Medium

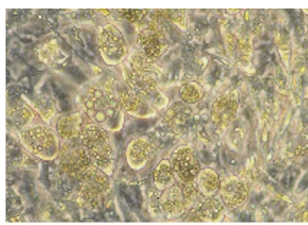

Insulin + MIBX

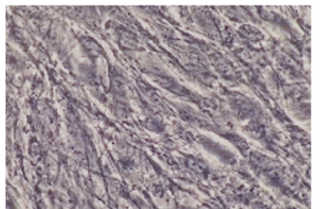

Insulin + MIBX

$+\mathrm{PGE}_{2}$

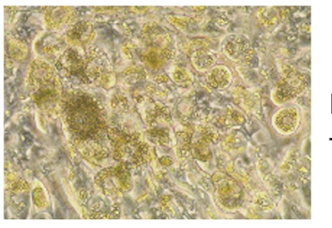

Insulin + MIBX + GST

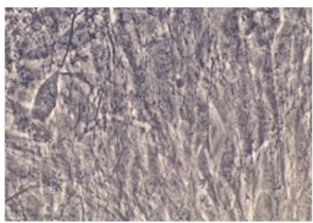

Insulin + MIBX

+ Adiponectin

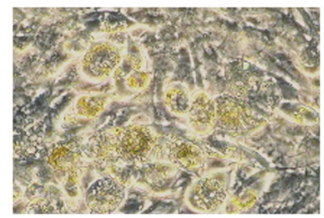

Insulin + MIBX

+ Adiponectin

+ Dup-697

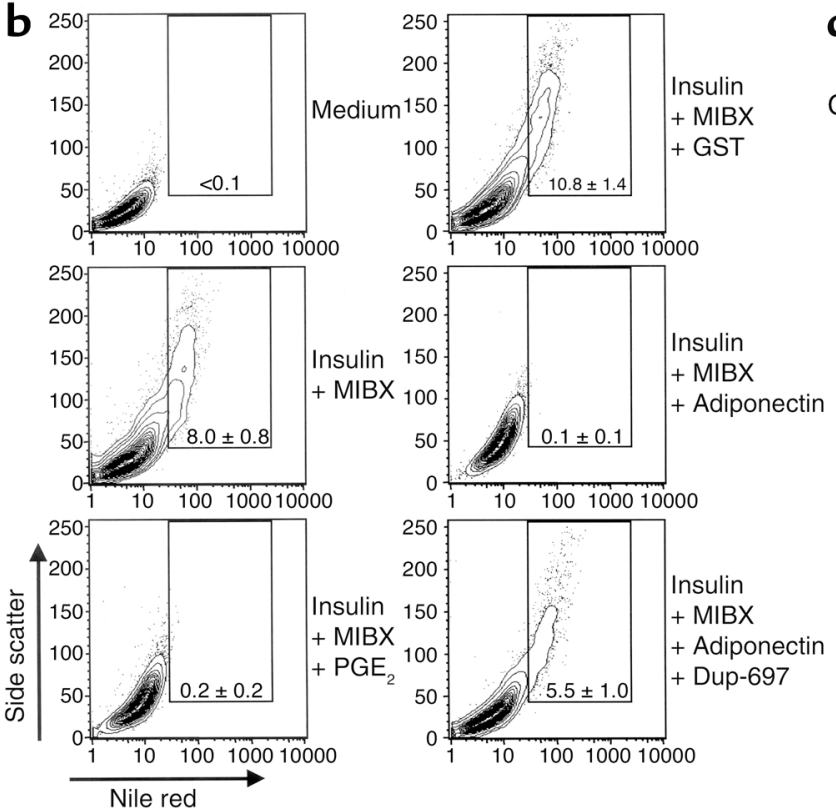

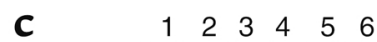

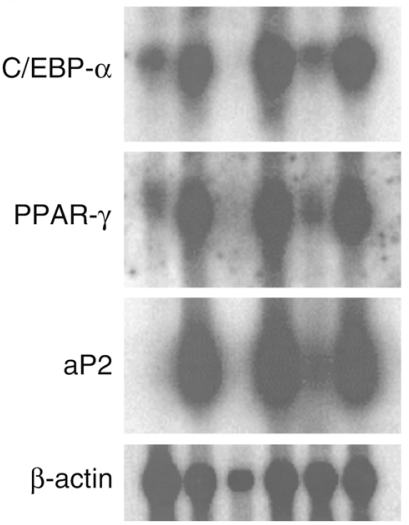

\section{Figure 4}

Adiponectin inhibits the differentiation of preadipocytes to adipocytes. Fat cell differentiation from BMS2 cells cultured with the indicated substances for 10 days in 24-well plates is illustrated in phase-contrast photomicrographs (a) and by flow cytometry with Nile red staining (b). The numbers in the boxes indicate the mean \pm SD percentages of adipocytes in triplicate cultures. The data are representative of that obtained in three similar experiments. (c) Expression of adipocyte-specific genes (C/EBP- $\alpha$, PPAR- $\gamma$, and aP2 $)$ and $\beta$-actin in BMS2. Poly $(A)^{+}$mRNA was isolated from BMS2 cells cultured under the indicated conditions and subjected to Northern blot analysis. Lane 1, medium alone; lane 2, insulin + MIBX; lane 3, insulin + MIBX + $\mathrm{PGE}_{2}$; lane 4, insulin + MIBX + GST; lane 5 , insulin + MIBX + adiponectin; lane 6 , insulin + MIBX + adiponectin + Dup-697.
(36) was detectable by RT-PCR, but this expression was not obviously influenced by adiponectin (data not shown). In contrast, we consistently found that transcripts for COX-2 but not COX-1 were upregulated by adiponectin treatment of either MS5 or BMS2 stromal cell clones (data not shown). We confirmed these observations by Northern blot analysis (Figure $3 \mathrm{a}$ ). $\mathrm{PGE}_{2}$ is known to inhibit adipogenesis and is a substance that depends on COX-2 for its production $(37,38)$. Therefore, BMS2 or MS5 cells were allowed to come to confluence before addition of either adiponectin or BSA (Figure $3 \mathrm{~b}$ ). $\mathrm{PGE}_{2}$ concentrations in the supernatants of these cultures were evaluated by ELISA at the indicated times. Adiponectin consistently caused approximately twofold increases in $\mathrm{PGE}_{2}$ secretion. Thus, $\mathrm{PG}$ synthesis represents a potential mechanism for inhibition of adipogenesis by adiponectin.

Responses of preadipocytes to adiponectin require COX-2. We then used two experimental approaches to assess the importance of COX-2 for the inhibition of fat cell formation by adiponectin. BMS2 cells were cultured with MIBX and insulin to induce strong fat cell formation, and this response was blocked as expected by inclusion of $\mathrm{PGE}_{2}$ in the medium (Figure 4a). Adiponectin also blocked adipogenesis, whereas a control GST fusion protein had no influence. The inhibition by adiponectin was not observed when the specific COX-2 inhibitor Dup-697 was present (Figure 4a). Inclusion of Dup-697 alone had no influence on fat cell formation (not shown). While accumulation of visible fat droplets was blocked by either $\mathrm{PGE}_{2}$ or adiponectin, the combination of insulin and MIBX still caused a morphological change in adherent layers relative to those in cultures with medium alone (Figure 4a). Flow cytometry and Nile red staining of the same cultures was therefore used to extend the microscopic analysis (Figure 4b). Lipid accumulation induced by insulin and MIBX was completely blocked by either $\mathrm{PGE}_{2}$ or adiponectin. The 

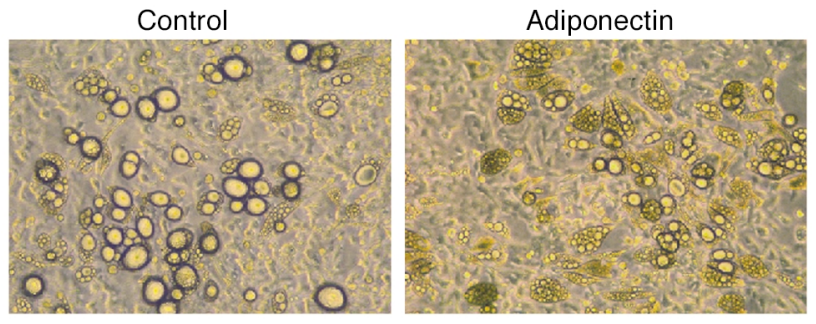

\section{Figure 5}

Preadipocytes from $\mathrm{COX}-2^{+/-}$mice are resistant to adiponectin. Fat cells were conspicuous in adherent layers of bone marrow cultures established from heterozygous $\mathrm{COX}-2^{+/-}$mice, as illustrated with these phase-contrast photomicrographs. Similar results were obtained in two independent experiments.

response to adiponectin was substantially blocked by inclusion of the COX-2 inhibitor. Adipocyte gene expression analysis confirmed the cell morphology and lipid accumulation findings (Figure 4c). C/EBP- $\alpha$ and PPAR- $\gamma$, two transcription factors crucial for adipogenesis, were only weakly expressed in BMS2 preadipocytes, but were intensely induced by insulin and MIBX. Either $\mathrm{PGE}_{2}$ or adiponectin strongly inhibited these increases, and Dup-697 again abrogated the induction by adiponectin. The results were very similar with respect to transcripts for the adipocyte-selective fatty acid-binding protein $\mathrm{aP} 2$.

Adherent bone marrow cell cultures were then prepared with wild-type or heterozygous knockout $\mathrm{COX}-2^{+/-}$ mice under conditions that favored the formation of numerous fat cells (see Methods). While adiponectin blocked adipogenesis in cultures of normal C57BL/6 bone marrow cells (data not shown), there was minimum effect on cells derived from $\mathrm{COX}-2^{+-}$animals (Figure 5). These results provide strong evidence that adiponectin directly blocks formation of adipocytes from fat cell precursors through a mechanism that requires induction of COX-2.

\section{Discussion}

The fat cell product known as adiponectin, Acrp30, adipoQ, or GBP28 is attracting interest because of its potential involvement in obesity, diabetes, and cardiovascular diseases. It was originally discovered in human subcutaneous fat tissue, in plasma, and in murine adipocyte lines, but our understanding of its normal distribution and biological activities is incomplete. We now show that adiponectin is present within normal bone marrow and can inhibit fat cell formation by marrow-derived stromal cells through a COX-2-dependent mechanism. These findings suggest a new mechanism for regulation of preadipocyte differentiation and possible roles for fat in hematopoietic tissue.

It is important to stress that all of these experiments were conducted with two batches of recombinant adiponectin that were produced by expression in $E$. coli and then subjected to protein refolding (see Methods). A monoclonal adiponectin-specific antibody neutralized the biological activity (data not shown), and no responses were recorded using recombinant GST fusion protein prepared from E. coli. The native protein has a complex, multimeric structure, and some groups have found that biological activity is improved by cleavage of $E$. coli-produced material, or by expression in mammalian cells $(26,27)$. On the other hand, there is one report that glucose and fatty acid levels in plasma were reduced by both full-length and cleaved material that was produced in bacteria (25). We found that $10 \mu \mathrm{g} / \mathrm{ml}$ concentrations of our recombinant adiponectin inhibited fat cell formation, and these amounts correspond to reported physiological levels (22). Our preparations contained multiple species that ranged in size from $34 \mathrm{kDa}$ to 500 $\mathrm{kDa}$ (Figure $2 \mathrm{~b}$ ), so it is possible that particular sizeseparated fractions would be especially active.

Adipocytes are increasingly regarded as participants in endocrine processes, producing substances that range from hormones to cytokines (39). Of particular interest are feedback mechanisms through which fat cell products inhibit adipogenesis. Adipocyte products known to have either direct or indirect inhibitory potential on adipose tissue include leptin, PAI-1, IFNs, TNF- $\alpha$, TGF- $\beta$, and PGE 2 (11-14). Additional substances are thought to influence such diverse processes as energy metabolism, immune responses, blood circulation, and reproduction (14). We now describe another fat cell product with the potential to inhibit fat cell differentiation.

Active hematopoietic marrow is progressively replaced by fat as part of normal aging (30). Adiponectin was detected in marrow adipocytes by immunostaining, and a high local concentration would presumably be able to prevent further fat cell formation. However, we do not know if it is actively secreted in that site or indeed how its release is controlled in other tissues. Animal studies show that fat cells are required to produce adiponectin, but do not explain why plasma levels are reduced in obese individuals (25).

Our data indicate that the COX-2-dependent prostanoid pathway is important for the suppressive activity of adiponectin on fat cell formation. The response of preadipocytes from $\mathrm{COX}-2^{+/-}$mice to adiponectin was negligible. Poor viability of homozygous $\mathrm{COX}-2^{-/-}$mice precluded their use in our experiments, and adiponectin unresponsiveness of the heterozygotes suggests a substantial gene dose effect. Furthermore, a COX-2 inhibitory compound blocked the inhibition of fat cell formation in cultures of cloned preadipocytes. COX-2 is induced in response to proinflammatory cytokines or hormones, and is a ratelimiting enzyme in the biosynthesis of PGs. It mediates the conversion of arachidonic acid into $\mathrm{PGH}_{2}$, which is subsequently converted to various kinds of PGs by specific synthases (38). PGs appear to contribute to fat cell formation in complex ways. For example, $\mathrm{PGE}_{2}$ and prostacyclin $\left(\mathrm{PGI}_{2}\right)$, the two major PGs synthesized by fat cells $(10,40)$, appear to have 
opposing actions on adipogenesis. $\mathrm{PGE}_{2}$ was shown to negatively regulate fat cell development by reducing cAMP production (37). Conversely, $\mathrm{PGI}_{2}$ is proposed as an adipogenic agonist (41). Our data confirm the inhibitory effect of $\mathrm{PGE}_{2}$ on marrow fat cell differentiation, and further suggest an important contribution to the inhibitory influence adiponectin has on adipogenesis. Other PGs that influence fat cell development include $\mathrm{PGJ}_{2}$, an important ligand for the adipogenic transcription factor PPAR- $\gamma$. This PG promotes adipocyte differentiation $(4,5)$. In contrast, $\mathrm{PGF}_{2 \alpha}$ inhibits the adipogenic differentiation of 3T3-L1 cells (42). Again, PGs with opposing actions are synthesized from $\mathrm{PGH}_{2}$, a COX-2 product. In our hands, the 3T3-L1 line generated fat cells in standard culture medium where insulin was the only inducing agent, and this differentiation was minimally affected by addition of either adiponectin or $\mathrm{PGE}_{2}$ (data not shown). Comparison of 3T3-L1 cells to adiponectinsensitive preadipocytes should be informative about inducible genes and could reveal functional heterogeneity among fat cells in normal tissues.

Two other adipocyte products, agouti and angiotensin II (AGT II), are known to contribute to obesity $(43,44)$. Agouti induces fatty acid and triglyceride synthesis in cultured adipocytes in a calcium influx-dependent manner (45). AGT II expression is nutritionally regulated, increasing with high-fat diet and fatty acids concomitant with fat mass (46). Adiponectin expression is also affected by diet, but the direction is contrary to that of AGT II (25). AGT II promotes adipocyte differentiation by stimulating release of $\mathrm{PGI}_{2}$ from mature adipocytes (41). Thus, PG synthesis appears to play an indispensable role in paracrine actions of adipocyte products on fat cell differentiation.

There are very interesting parallels and functional relationships between adiponectin and TNF- $\alpha$. The three-dimensional structure of the $\mathrm{C}$-terminal globular domain of adiponectin is strikingly similar to that of TNF- $\alpha(19)$. Both molecules are secreted from fat cells, and both directly inhibit fat cell development. However, their physiological levels and actions can be quite different. Plasma levels of adiponectin decrease in obese individuals, while concentrations of TNF- $\alpha$ are reported to increase and may contribute to insulin resistance and diabetes (8). In contrast, two recent reports suggest that adiponectin may be useful for treatment of type II diabetes $(25,26)$. Adiponectin inhibits TNF- $\alpha$ production in macrophages (29), while TNF- $\alpha$ suppresses adiponectin expression in adipocytes (20). TNF- $\alpha$ stimulates NF- $\mathrm{KB}$ signaling in aortic endothelial cells, leading to increased expression of adhesion molecules, but adiponectin inhibits this process (28). Therefore, two structurally similar proteins appear to have opposing functions, and defects in this delicate balance may result in susceptibility to obesity-related diseases.

Much work remains to establish the importance of adiponectin to normal, steady-state, and disease processes. Brown fat cells that reside in bone marrow are potential sources of PGs, sex steroids, and cytokines that could have a major influence on lymphohematopoiesis. It is interesting that while adiponectin inhibits differentiation of isolated macrophage progenitors in clonal assays (29), it does not block myelopoiesis in LTBMCs. On the other hand, B lymphopoiesis in complex cultures is blocked by adiponectin through a stromal cell PG-dependent mechanism (unpublished observations). These findings raise interesting questions about functional relationships between preadipocyte stromal cells, adipocytes, and lymphohematopoietic progenitor cells within bone marrow.

It will also be important to learn whether white fat located in nonhematopoietic tissues produces PGs in direct response to adiponectin. It was recently reported that fragments of murine adiponectin decreased body weights when injected into mice on high-fat, high-calorie diets (27). The response was thought to involve increased fatty acid oxidation in muscle, resulting in the reduction of plasma fatty acid levels. Our experiments focused on bone marrow-derived preadipocytes and showed that they are direct adiponectin targets. Studies are underway to determine if lipid accumulation decreases in well-differentiated marrow fat cells following exposure to this substance.

Stem cells of various kinds are being extensively studied because of their potential for repairing adult tissues. Some cloned preadipocyte lines derived from bone marrow have been termed mesenchymal stem cells because of their extensive self-renewal capacity and ability to generate multiple cell types (1). Paracrine factors such as adiponectin that are made by differentiated stromal cells may contribute to properties that can be harnessed for therapeutic applications. Our findings should stimulate additional investigation of adiponectin activities and responsive cell types.

\section{Acknowledgments}

The authors are grateful to Linda Thompson and John J.T. Owen for their critical reading of the manuscript. We thank Kouichi Osaki for his expert help with gel filtration chromatography. We also thank Karla Garret, Michelle Robertson, and Sophia Gregory for their technical assistance, as well as Viji Dandapani for her help with flow cytometry. The secretarial assistance provided by Shelli Wasson is also appreciated. This work was supported by NIH grants AI-45864, AI-33085, and AI-20069. P.W. Kincade holds the William H. and Rita Bell Chair in biomedical research.

\footnotetext{
1. Pittenger, M.F., et al. 1999. Multilineage potential of adult human mesenchymal stem cells. Science. 284:143-147.

2. Gimble, J.M., et al. 1990. Adipogenesis in a murine bone marrow stromal cell line capable of supporting B lineage lymphocyte growth and proliferation: biochemical and molecular characterization. Eur. J. Immunol. 20:379-387.

3. Russell, T.R., and Ho, R. 1976. Conversion of 3 T3 fibroblasts into adipose cells: triggering of differentiation by prostaglandin F2alpha and 1-methyl-3-isobutyl xanthine. Proc. Natl. Acad. Sci. USA. 73:4516-4520.

4. Forman, B.M., et al. 1995. 15-deoxy-delta 12,14-prostaglandin J2 is a ligand for the adipocyte determination factor PPAR gamma. Cell. 83:803-812.
} 
5. Kliewer, S.A., et al. 1995. A prostaglandin J2 metabolite binds peroxisome proliferator-activated receptor gamma and promotes adipocyte differentiation. Cell. 83:813-819.

6. Zhang, Y., et al. 1994. Positional cloning of the mouse obese gene and its human homologue. Nature. 372:425-432.

7. Shimomura, I., et al. 1996. Enhanced expression of PAI-1 in visceral fat: possible contributor to vascular disease in obesity. Nat. Med. 2:800-803.

8. Hotamisligil, G.S., Shargill, N.S., and Spiegelman, B.M. 1993. Adipose expression of tumor necrosis factor-alpha: direct role in obesity-linked insulin resistance. Science. 259:87-91.

9. Richardson, R.L., Campion, D.R., Hausman, G.J., and Wright, J.T. 1989 Transforming growth factor type beta (TGF-beta) and adipogenesis in pigs. J. Anim. Sci. 67:2171-2180.

10. Hyman, B.T., Stoll, L.L., and Spector, A.A. 1982. Prostaglandin production by 3T3-L1 cells in culture. Biochim. Biophys. Acta. 713:375-385.

11. Thomas, T., et al. 1999. Leptin acts on human marrow stromal cells to enhance differentiation to osteoblasts and to inhibit differentiation to adipocytes. Endocrinology. 140:1630-1638.

12. Crandall, D.L., Busler, D.E., McHendry-Rinde, B., Groeling, T.M., and Kral, J.G. 2000. Autocrine regulation of human preadipocyte migration by plasminogen activator inhibitor-1. J. Clin. Endocrinol. Metab. 85:2609-2614.

13. Gimble, J.M., et al. 1989. Response of bone marrow stromal cells to adipogenic antagonists. Mol. Cell. Biol. 9:4587-4595.

14. Kim, S., and Moustaid-Moussa, N. 2000. Secretory, endocrine and autocrine/paracrine function of the adipocyte. J. Nutr. 130:3110S-3115S.

15. Scherer, P.E., Williams, S., Fogliano, M., Baldini, G., and Lodish, H.F. 1995. A novel serum protein similar to C1q, produced exclusively in adipocytes. J. Biol. Chem. 270:26746-26749.

16. Hu, E., Liang, P., and Spiegelman, B.M. 1996. AdipoQ is a novel adiposespecific gene dysregulated in obesity. J. Biol. Chem. 271:10697-10703.

17. Maeda, K., et al. 1996. cDNA cloning and expression of a novel adipose specific collagen-like factor, apM1 (Adipose Most Abundant Gene Transcript 1). Biochem. Biophys. Res. Commun. 221:286-289.

18. Nakano, Y., Tobe, T., Choi-Miura, N.H., Mazda, T., and Tomita, M. 1996. Isolation and characterization of GBP28, a novel gelatin-binding protein purified from human plasma. J. Biochem. (Tokyo). 120:803-812.

19. Shapiro, L., and Scherer, P.E. 1998. The crystal structure of a complement-1q family protein suggests an evolutionary link to tumor necrosis factor. Curr. Biol. 8:335-338.

20. Kappes, A., and Loffler, G. 2000. Influence of ionomycin, dibutyrylcycloAMP and tumour necrosis factor-alpha on intracellular amount and secretion of apM1 in differentiating primary human preadipocytes. Horm. Metab. Res. 32:548-554

21. Bogan, J.S., and Lodish, H.F. 1999. Two compartments for insulin-stimulated exocytosis in 3T3-L1 adipocytes defined by endogenous ACRP30 and GLUT4. J. Cell Biol. 146:609-620.

22. Arita, Y., et al. 1999. Paradoxical decrease of an adipose-specific protein, adiponectin, in obesity. Biochem. Biophys. Res. Commun. 257:79-83.

23. Ouchi, N., et al. 1999. Novel modulator for endothelial adhesion molecules. Adipocyte-derived plasma protein adiponectin. Circulation. 100:2473-2476.

24. Hotta, K., et al. 2001. Circulating concentrations of the adipocyte protein adiponectin are decreased in parallel with reduced insulin sensitivity during the progression to type 2 diabetes in rhesus monkeys. Diabetes. 50:1126-1133.

25. Yamauchi, T., et al. 2001. The fat-derived hormone adiponectin reverses insulin resistance associated with both lipoatrophy and obesity. Nat. Med. 7:941-946.

26. Berg, A.H., Combs, T.P., Du, X., Brownlee, M., and Sherer, P.E. 2001. The adipocyte-secreted protein Acrp30 enhances hepatic insulin action. Nat Med. 7:947-953.

27. Fruebis, J., et al. 2001. Proteolytic cleavage product of $30-\mathrm{kDa}$ adipocyte complement-related protein increases fatty acid oxidation in muscle and causes weight loss in mice. Proc. Natl. Acad. Sci. USA. 98:2005-2010.

28. Ouchi, N., et al. 2000. Adiponectin, an adipocyte-derived plasma protein, inhibits endothelial NF-kappaB signaling through a cAMP-dependent pathway. Circulation. 102:1296-1301.

29. Yokota, T., et al. 2000. Adiponectin, a new member of the family of soluble defense collagens, negatively regulates the growth of myelomonocytic progenitors and the functions of macrophages. Blood. 96:1723-1732.

30. Gimble, J.M., Robinson, C.E., Wu, X., and Kelly, K.A. 1996. The function of adipocytes in the bone marrow stroma: an update. Bone. 19:421-428.

31. Umezawa, A., et al. 1991. Colony stimulating factor 1 expression is down-regulated during adipocyte differentiation of $\mathrm{H}-1 / \mathrm{A}$ marrow stromal cells and induced by cachectin/tumor necrosis factor. Mol. Cell. Biol. 11:920-927.

32. Nishikawa, M., et al. 1993. Changes in hematopoiesis-supporting ability of C3H10T1/2 mouse embryo fibroblasts during differentiation. Blood. 81:1184-1192.

33. Umemoto, Y., et al. 1997. Leptin stimulates the proliferation of murine myelocytic and primitive hematopoietic progenitor cells. Blood. 90:3438-3443.

34. Dexter, T.M., and Testa, N.G. 1976. Differentiation and proliferation of hemopoietic cells in culture. Methods Cell Biol. 14:387-405.

35. Gimble, J.M., et al. 1995. Bone morphogenetic proteins inhibit adipocyte differentiation by bone marrow stromal cells. J. Cell. Biochem. 58:393-402.

36. Oritani, K., et al. 2000. Limitin: an interferon-like cytokine that preferentially influences B-lymphocyte precursors. Nat. Med. 6:659-666.

37. Vassaux, G., Gaillard, D., Darimont, C., Ailhaud, G., and Negrel, R. 1992. Differential response of preadipocytes and adipocytes to prostacyclin and prostaglandin E2: physiological implications. Endocrinology. 131:2393-2398

38. Goetzl, E.J., An, S., and Smith, W.L. 1995. Specificity of expression and effects of eicosanoid mediators in normal physiology and human diseases. FASEB J. 9:1051-1058.

39. Matsuzawa, Y., Funahashi, T., and Nakamura, T. 1999. Molecular mechanism of metabolic syndrome $\mathrm{X}$ : contribution of adipocytokines adipocyte-derived bioactive substances. Ann. NY Acad. Sci. 892:146-154.

40. Richelsen, B. 1992. Release and effects of prostaglandins in adipose tissue. Prostaglandins Leukot. Essent. Fatty Acids. 47:171-182.

41. Darimont, C., Vassaux, G., Ailhaud, G., and Negrel, R. 1994. Differentiation of preadipose cells: paracrine role of prostacyclin upon stimulation of adipose cells by angiotensin-II. Endocrinology. 135:2030-2036.

42. Miller, C.W., Casimir, D.A., and Ntambi, J.M. 1996. The mechanism of inhibition of 3T3-L1 preadipocyte differentiation by prostaglandin F2alpha. Endocrinology. 137:5641-5650.

43. Klebig, M.L., Wilkinson, J.E., Geisler, J.G., and Woychik, R.P. 1995. Ectopic expression of the agouti gene in transgenic mice causes obesity, features of type II diabetes, and yellow fur. Proc. Natl. Acad. Sci. USA. 92:4728-4732.

44. Cassis, L.A. 1994. Angiotensin II in brown adipose tissue from young and adult Zucker obese and lean rats. Am. J. Physiol. 266:453-458.

45. Jones, B.H., et al. 1996. Upregulation of adipocyte metabolism by agouti protein: possible paracrine actions in yellow mouse obesity. Am. J. Physiol. 270:E192-E196.

46. Safonova, I., Aubert, J., Negrel, R., and Ailhaud, G. 1997. Regulation by fatty acids of angiotensinogen gene expression in preadipose cells Biochem. J. 322:235-239. 